https://doi.org/10.46344/JBINO.2021.v10i03.13

\title{
A SIMPLE AND INEXPENSIVE THIN LAYER CHROMATOGRAPHY TECHNIQUE TO COMPARE PORK AND BEEF FOR HALAL AUTHENTICATION
}

\author{
Muhammad Ja'far Luthfi \\ Biological Education Department ,Faculty of Tarbiyah \& Education UIN Sunan Kalijaga Yogyakarta \\ email: jafarluthfi@yahoo.com
}

\begin{abstract}
Nowadays, there are many cases of adulteration of beef with pork. Pork can be found by analyzing the fat. Meat contains fat whose biochemical profile differs between animal species. Based on this principle, we could determine authenticity of given meat by comparing its fat profile. This study aims to develop a thin layer chromatography (TLC) technique to detect pork and determine the chromatographic difference of beef and pork fat. The study revealed that TLC method can be performed to detect pork. TLC was carried out using the hexane-chloroform-methanol (7: 2.5: 1, volume ratio) solvent system. Using this method there were differences in the number of spots and the Rf value between beef and pork fat. Overall, TLC is a method that has the potential to be used as an inexpensive and simple tool for the detection of pork.
\end{abstract}

Keywords: thin layer chromatography, pork detection, halal authentication, lipid TLC 


\section{Introduction}

Islam is one of the largest populations with over 1.4 billion Muslims worldwide and this is expected to increase further. Muslims have their specialty for food labelling and traceability of food products. Halal food represents $17 \%$ of the global food industry and is worth around $\$ 600$ billion annually (Thomas et al., 2015; Martuscelli et al., 2020).

Muslims are prohibited to consume pork. Pork is one of the nonhalal foods in Islamic belief. However, it is not easy to differentiate pork from beef. Nowadays, there are many cases of beef adulteration or substitution with pork which are carried out by market traders to get more profit because the price of pork is relatively cheaper than the price of beef. Some traders even smear cow blood all over the pork, making the characteristic and distinctive smell of pork is not quite obvious (Fikri et al., 2004).

The presence of pork can be detected by analyzing its fat. Meat contains fat whose biochemical profile differs between animal species. This difference in the biochemical profile of the lipids is the basis for the detection of pork fat. Pork fat detection are carried out by analyzing the fatty acid methyl esters using a gas chromatography mass spectrometry (Sumartini et al. 2003) or gas chromatography flame ionisation detector (GC-FID) (Dahimi et al., 2014). The techniques, however, need sophisticated equipment not available in many laboratories. They are too technically complex and too expensive for routine use.
Thin layer chromatography (TLC) is a chromatographic technique that has long been used in chemical separation methods (Hahn-Deinstrop, 2007). This method uses silica gel on glass/aluminum media as the stationary phase, and a combination of organic solvents as the mobile phase. In summary, the principle is the separation of the sample placed on silica, which moves apart along with the upward movement of the moving phase in the stationary phase. Apart from being used to isolate pure compounds, TLC is also used for the qualitative analysis of complex mixtures of biological matter. Different materials will give different chromatogram images. Because meat contains fat which is biochemically different among animal species, theoretically the TLC chromatogram of fat will be different for each type of animal (Cristie, 1990; Mason et al., 1987; Cristie \& Dobson 1999; Touchstone, 1995; Weldon \& Bagnall, 1987; Robert-Peillard et al., 2019).

Louis-Ferdinand et al. (1967) in their research entitled "Application of Thin-layer Chromatography to the Quantitation of Plasma Neutral Lipids and Free Fatty Acid" studied the comparison of the use of TLC with standard chemical procedures in the quantification of plasma lipids and free fatty acids. The results show that the two methods were not significantly different.

The very rapid development and widespread application of HighPerformance Liquid Chromatography (HPLC) halted the potential development of TLC in many laboratories. TLC is considered too time-consuming and 
labor-consuming, and requires special skills and attention. However, this assumption is not entirely correct. TLC is not an automatic tool, but it is easy to use and does not require expensive equipment. It is a single chromatographic technique that can provide an overall picture of the composition of a sample, thus providing quick identification of the compound as the sample and reference components are applied to the same plate under identical conditions. The use of TLC technique appropriately promises results that are not inferior to HPLC (Christie, 2003; Henderson \& Tocher, 1992; Momchilova \& Nikolova-Damyanova, 2008).

Although it is an old technology, TLC is relatively easy to use, simple, and has the similar capabilities as other chromatography methods (Momchilova \& Nikolova-Damyanova, 2008; Petrovic \& Cani, 1969; Anderson et al., 1974). This characteristic underlies the need for the development of detection of pork by the TLC method. The detection using a simple, inexpensive, and easy but reliable tool will help Muslim communities from all regions to recognize the presence of pork.

In this article, a simple and inexpensive TLC technique for the detection of pork was developed. The method is intended as an analytical tool for differentiate pork and beef in laboratory which cannot afford HPLC and GC testing. Development and application of this procedure for qualitative determination of pork are presented herein.

\section{Methods}

\section{Materials}

\section{I.1. Samples}

Pork and beef were obtained from the market in Sleman, Yogyakarta, Indonesia.

\subsection{Chemical}

Chemical used in this study were silica gel, acetone, methanol, hexane, absolute ethanol, 70\% ethanol, tolvene, sulfuric acid, butanol, petroleum ether and Merck 60 F254 (1.05735) silica gel plate (Merck, Germany).

\section{Equipment}

The equipment used in this study were as follows: a set of in-house preparative thin layer chromatography, pipette, oven, glassware, laminar airflow cabinet, rotary evaporator, filter paper, capillary tube, camera, and an ultraviolet light device.

\section{Procedure}

\subsection{Fat extraction}

In this study, fat extraction was done using hexane. Hexane is the most common solvent of choice for lipid extractions due to its technical and economic advantages, especially its high selectivity toward lipids and low cost (Shin et al., 2018). The fats were separated from the meats. One hundred grams of fat (pork and beef, respectively) were chopped. The fat was macerated with hexane for two days and then filtered. The filtrate was evaporated by rotary evaporator. The extract was stored at $4^{\circ}$ C until use. 


\subsection{Thin layer chromatography technique}

Thin layer chromatography technique was used to detect the fat components profile contained in the samples. A set of solvent systems were used to find the suitable one for the differentiation of profile character of pork and beef fat chromatogram.

The TLC plate used was the Merck 60 F254 (1.05735) silica gel plate. The sample to be analyzed was slightly dissolved with the appropriate solvent, and then it was spotted onto the TLC plate using a capillary tube at a distance of approximately $1 \mathrm{~cm}$ from the bottom of the plate. While waiting for the sample droplets to dry, the chromatography tank was filled with a suitable solvent system, closed and allowed to saturate with solvent vapor. Then the TLC plate that had spotted with the sample was inserted into the saturated chromatography tank on an inclined position against the tank wall. The development of the solvent was allowing solvent to move up along the plate until it reaches a distance of approximately $1 \mathrm{~cm}$ from the top end of the plate. The TLC plate was removed from the tank and the solvent distance was marked before the solvent on the plate was dry in the air.

\subsection{Analysis of fat profiles on the TLC plate}

The TLC plates were viewed under an ultraviolet light at a wavelength of 254, $356 \mathrm{~nm}$ to identify the components and profiles of pork and beef fat, respectively. Then, the visible components with the two ultraviolet rays was photographed to obtain a chromatogram. The difference in chromatograms of pork and beef fat was described qualitatively. 


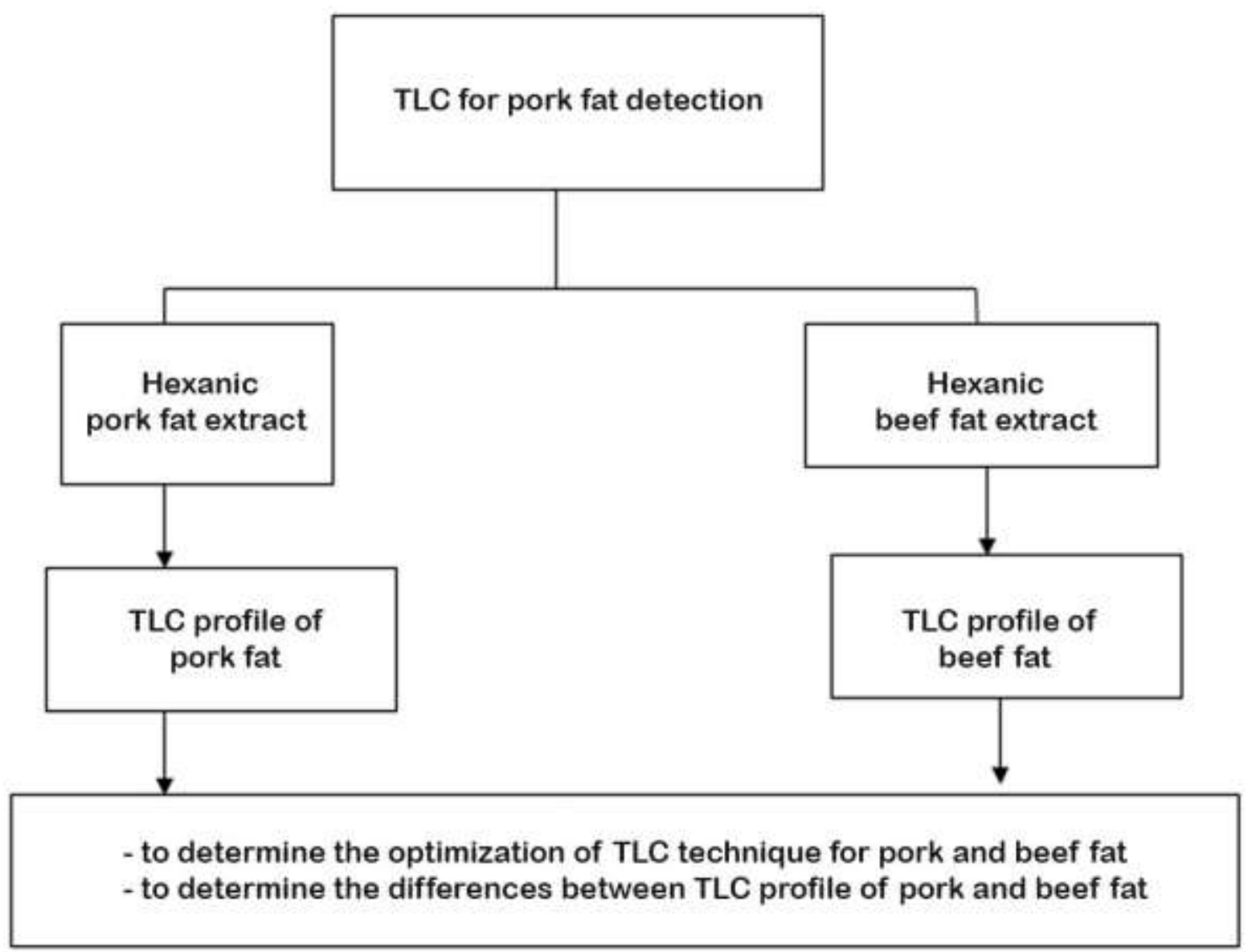

Figure 1. Flow chart of the research

\section{Result and discussion}

then filtered to produce hexane extract

Separation of pork and beef fat from its of pork and beef fat (Figure 2).

meat was followed by extraction

(maceration) using hexane for 2 days, 


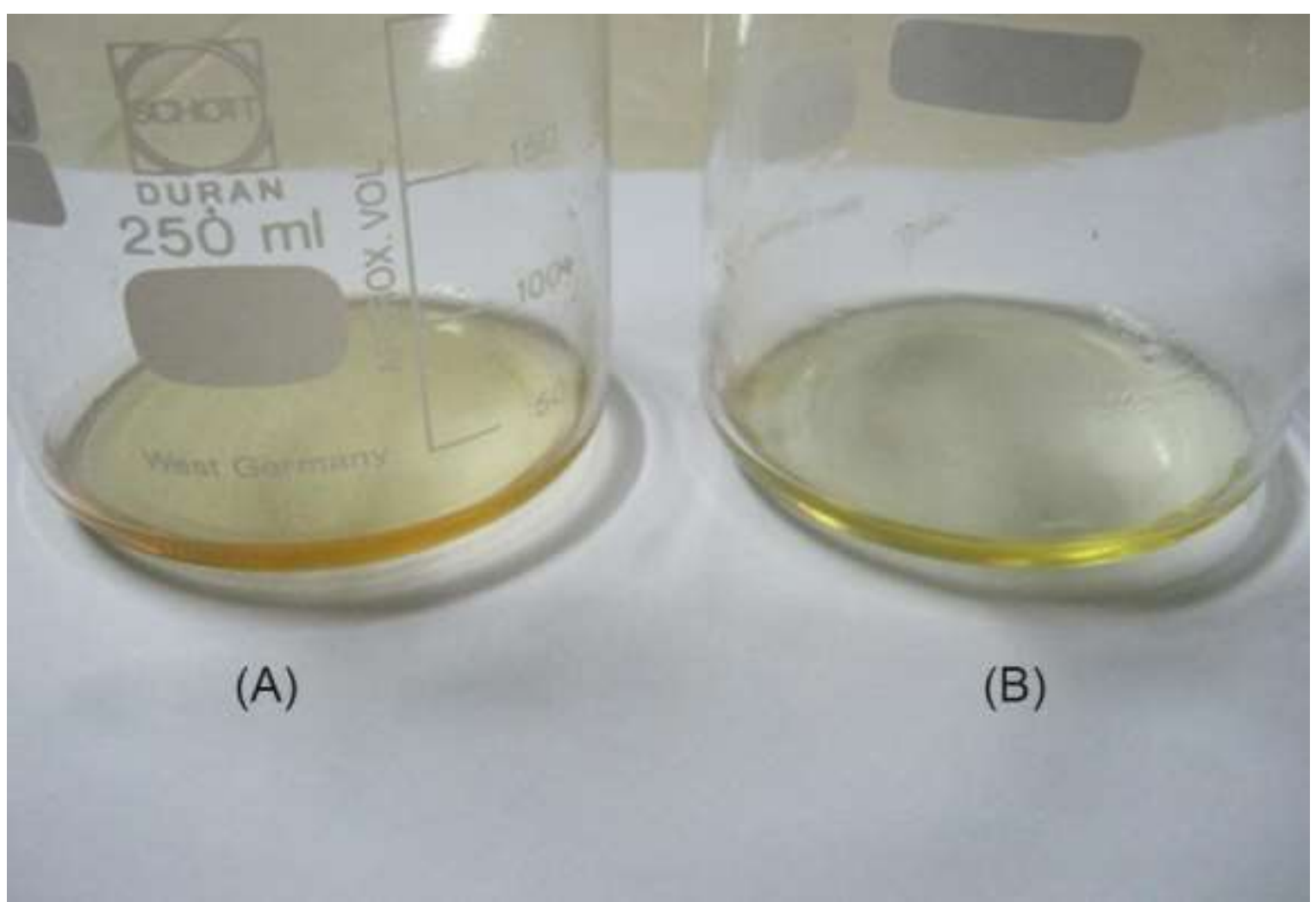

Figure 2. Hexanic extract of beef (A) and pork (B) fat.

Many organic solvents were used for TLC development with silica gel plates in this study. Thin layer chromatography of the hexanic extract of pork and beef fat found best result using the hexanechloroform-methanol ( $7: 2.5: 1$, volume ratio) solvent system, resulting in a chromatogram as shown in Figure 3. 


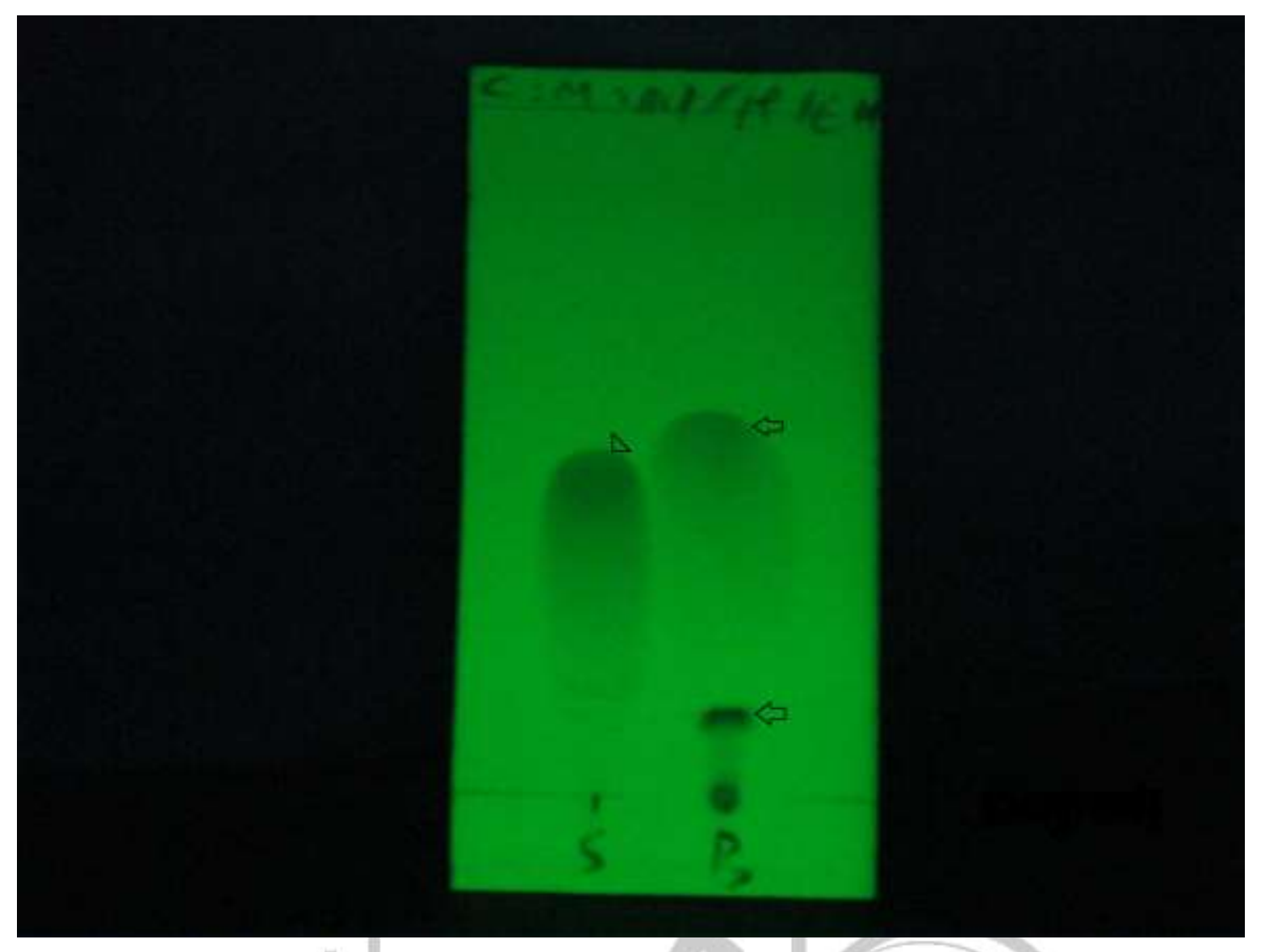

Figure 3. Hexanic extract of pork and beef fat chromatogram. Legend: S, beef fat; B, pork fat; Arrowhead, beef fat after development; Arrow, pork fat after development.

The qualitative analysis showed differences in the chromatogram of pork and beef fat profile. Figure 3 shows that the beef fat after TLC development revealed the presence of one spot, compared to the pork fat which shows two spots. In addition, the uppermost spot of the two samples had a difference in the Rf value, which was a consequence of the lower spot of beef fat compared to the pork one (Figure 4). The retention factor (Rf) was calculated from the chromatogram and was defined as the ratio of the distance traveled by the center of a sample spot to the distance traveled by the solvent front. The calculation showed that the highest spot Rf value for beef fat is 2.1/4.4 =0.47, while pork fat has 2.4/4.4 =0.54. The Rf value at the lower spot of pork fat, namely 1.7/4.4 $=0.38$, was not compared with beef fat given there is no spot at that point. 


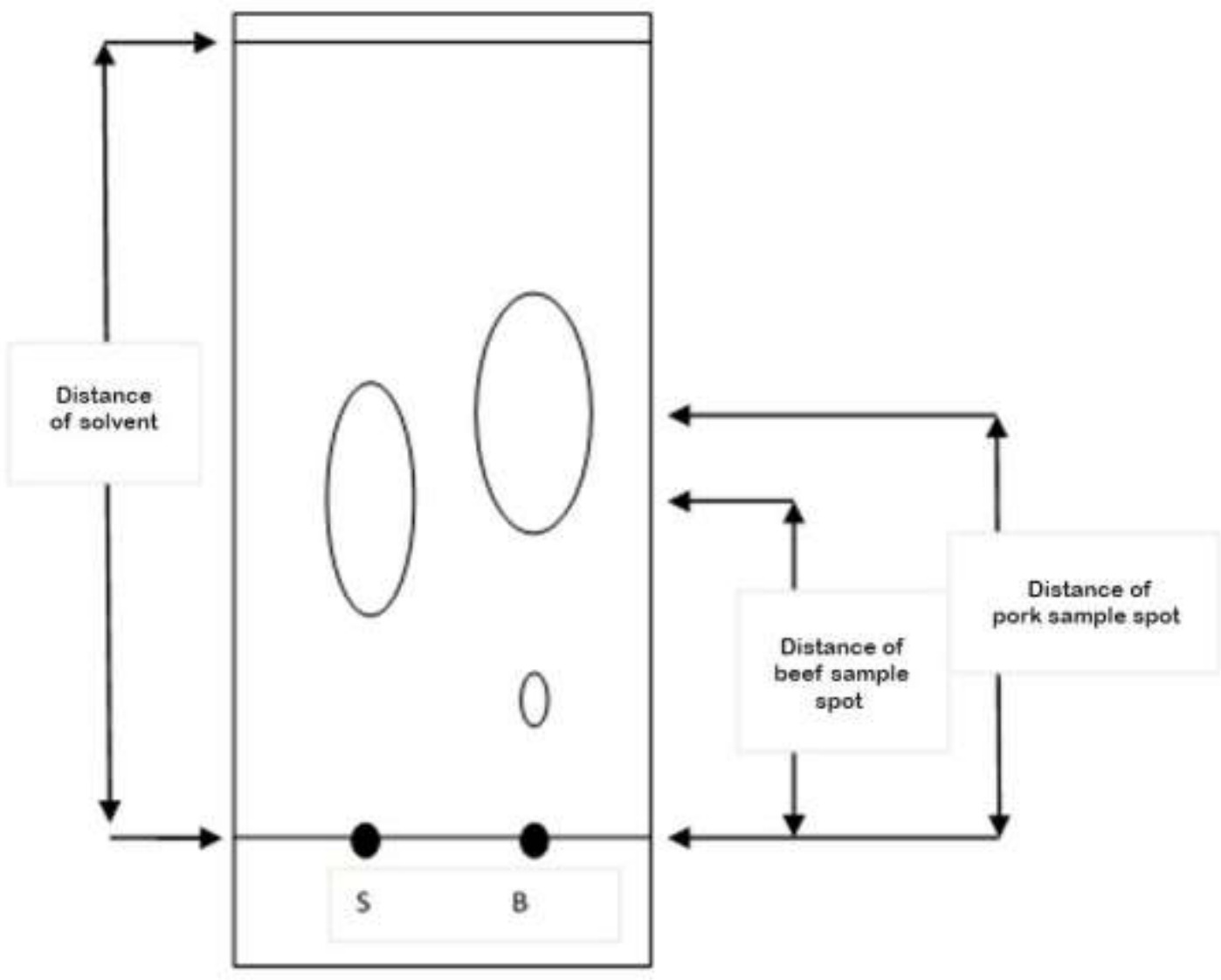

3. Schematic illustration of beef and pork fat chromatogram. Legend: S, beef fat; B, pork fat. Rf value was determined by formula as follows: $\mathrm{Rf}=$ distance of center spot/distance of solvent.

The results of this study revealed that TLC technique can be done to detect pork. TLC was carried out using the hexanechloroform-methanol (7: 2.5: 1, volume ratio) solvent system. Using this method there were differences in the number of spots and the Rf value after being developed between beef and pork fat.

\section{Conclusion}

It is demonstrated that detection using one of the simplest separation techniques (thin-layer chromatography) is indeed possible for halal authentication of meat. Overall, TLC is a method that has the potential to be used as an inexpensive and simple tool for the detection of pork.
Anderson, I.G., G.A.D. Haslewood, R.S. Oldham, B. Amosi, L. Tokis. 1974. A More Detailed Study of Bile Salt Evolution, Including Techniques for Small-Scale Identification and their Application to Amphibian Biles. Biochem. J. 141: 485-494.

Christie, W.W. 1990. Has thin-layer chromatography had its day? Lipid Technology 2: 22-23.

Christie, W.W. 2003. Lipid Analysis. 3rd Edition. Oily Press, USA.

Christie, W.W., G. Dobson. 1999. Thin-layer chromatography-revisited. Lipid Technology 11: 64-66. 
Dahimi, O., Hassan, M.S., Rahim, A.A., Abdulkarim, S.M., Mashitoh A, S. 2014. Differentiation of Lard from Other Edible Fats by Gas Chromatography Flame Ionisation Detector (GC-FID) and Chemometrics. J.Food Pharm.Sci. 2: 2731.

Fikri, A., E.P. Sigit, N.H. Afifah, T.S. Hendry, H. Rafiqa, I.O.S. Siti. 2004. Pengembangan kit diagnostic untuk deteksi daging babi dengan antibodi poliklonal. Buletin Penalaran Mahasiswa UGM 10 (2): 2-5.

Hahn-Deinstrop, E. 2007. Applied Thin-Layer Chromatography Best Practice and Avoidance of Mistake. Second edition.Wiley- $\mathrm{VCH}$ Verlag $\mathrm{GmbH}$ \& Co. KGaA.Weinheim, Germany.

Henderson, R.J., D.R. Tocher. 1992. Thin-layer chromatography. In Lipid Analysis. A Practical Approach ledited by R.J. Hamilton \& S. Hamilton). IRL Press. Oxford.

Louis-Ferdinand, R.T., D. G. Therriault, W. F. Blatt, M. Mager, E. J. Matheson. 1967. Application of Thin-layer Chromatography to the Quantitation of Plasma Neutral Lipids and Free Fatty Acids. Clinical Chemistry 13 (9): 773-787.

Martuscelli, M., Serio, A., Capezio, O., Mastrocola, D. 2020. "Safety, Quality and Analytical Authentication of halāl Meat Products, with Particular Emphasis on Salami: A Review" Foods 9, no. 8: 1111.

Mason, R.T., J.W. Chinn, D. Crews. 1987. Sex and seasonal differences in the skin lipids of garter snakes. Comp. Biochem. Physiol. 87B (4): 999-1003.
Momchilova, S., B. Nikolova-Damyanova. 2008. TLC of Lipids. in Thin Layer Chromatography in Phytochemistry (eds. M. Waksmundzka-Hajnos, et.al). CRC Press. New York.

Petrovic, S.M., V.D. Cani. 1969. Separation of Carbohydrates by Thin-layer Chromatography. Mikrochimica Acta 3: 599-604.

Robert-Peillard, F., Mattio, E., Komino, A., Boudenne, J., Coulomb, B. 2019. Development of a simple, low-cost and rapid thin-layer chromatography method for the determination of individual volatile fatty acids. Anal. Methods 11: 1891-1897.

Shin, HY., Shim, SH., Ryu, YJ. et al. Lipid Extraction from Tetraselmis sp. Microalgae for Biodiesel Production Using Hexanebased Solvent Mixtures. Biotechnol Bioproc E 23, 16-22 (2018).

Sumartini, S., O. Zuas, R. Julismardiany, E. Susilawati. 2003. Aplikasi elisa kit untuk mendeteksi adanya daging babi dalam makanan. Prosiding Seminar Tantangan Penelitian Kimia. Institut Pertanian Bogor. Bogor.

Thomas, A.M., White, G.R.T., Plant, E., Zhou, P. 2015. Challenges and practices in Halal meat preparation: a case study investigation of a UK slaughterhouse. Total Quality Management and Business Excellence. 28(1-2):1-20.

Touchstone, J.C. 1995.Thin-layer chromatographic procedures for lipid separation. J. Chromatogr. B. 671:169-195.

Weldon, P.J., D. Bagnall. 1987. A survey of 2 
polar and nonpolar skin lipids from lizards

by thin-layer

Comparative chromatography. Biochemistry and
Physiology Part B: Biochemistry 87 (2): 345-349. 